\title{
Smoking among older childbearing women - a marker of risky health behaviour a registry-based study in Finland
}

Reeta Lamminpää ${ }^{*}$, Katri Vehviläinen-Julkunen², Mika Gissler ${ }^{3}$ and Seppo Heinonen ${ }^{4}$

\begin{abstract}
Background: Smoking during pregnancy is known to negatively affect pregnancy outcomes and it has been associated with numerous complications during pregnancy. Smoking is more common in younger pregnant women, but previous research has shown that adverse pregnancy outcomes related to older maternal age and smoking are even more harmful than with younger smokers. The aim of this study was to compare pregnancy outcomes among smoking and non-smoking pregnant women aged $<35$ years and $\geq 35$ years.
\end{abstract}

Methods: In this registry-based study, the data were collected from three national Finnish health registries: Finnish Medical Birth Register, Finnish Hospital Discharge Register, and Register of Congenital Malformations between the years 1997 and 2008. The data included information on 80260 women who were smoking during pregnancy, of which 11277 (9\%) were $\geq 35$ years and 68983 (13\%) were <35 years old. In multivariate modelling, the main outcome measures were preterm delivery, low Apgar scores at 1 min., low birth weight, small for gestational age, fetal death and preeclampsia.

Results: Fewer older women smoked during pregnancy (9\%) than younger women did (13\%). Smoking increased the risk of adverse pregnancy outcomes, most in the older group. Multivariate logistic regression using non-smoking women aged $<35$ years as a reference group indicated that smoking women $<35$ years had higher rates of preterm delivery (OR 1.27 Cl 1.20-1.35), SGA (OR 2.18 Cl 2.10-2.26) and LBW (OR $1.73 \mathrm{Cl} 1.62-1.84)$.

Non-smoking women $\geq 35$ had higher rates of preterm delivery ( $\mathrm{OR} 1.15 \mathrm{Cl} 1.10-1.20)$, fetal death ( $\mathrm{OR} 1.36 \mathrm{Cl} 1.12-1.64)$, preeclampsia (OR $1.14 \mathrm{Cl} 1.09-1.20)$ and LBW (OR $1.13 \mathrm{Cl} 1.07-1.19)$.

Smoking women $\geq 35$ had higher rates of preterm delivery (OR $1.60 \mathrm{Cl} 1.40-1.82)$, SGA (OR $2.55 \mathrm{Cl}$ 2.34-2.79), fetal death (OR 2.70 Cl 1.80-4.05) and LBW (OR $2.50 \mathrm{Cl} 2.20-2.80)$.

Conclusions: Smoking during pregnancy increased the risk of adverse pregnancy outcomes in all women, but the rates were the highest for women aged $\geq 35$ years. Pregnant women aged $\geq 35$ years smoking during pregnancy was a distinctly high risk group. Maternity care should identify these women and support them in cessation of smoking during the first trimester of pregnancy.

Keywords: Smoking, Registry-based study, Pregnancy outcome, Older mothers

\footnotetext{
* Correspondence: reeta.lampinen@uef.fi

${ }^{1}$ Department of Nursing Science, University of Eastern Finland, P.O.Box. 1627,

70211 Kuopio, Finland

Full list of author information is available at the end of the article
} 


\section{Background}

Approximately 250 million women worldwide are daily smokers. The prevalence of smoking women is $22 \%$ in developed countries and 9\% in developing countries. During pregnancy, approximately over $10 \%$ of women smoke, and the prevalence of smoking was the highest for women aged 18-19 years old (26\%) [1,2].

Smoking during pregnancy is one of the major issues impairing the prognosis of pregnancy [3]. In Finland, the proportion of women who smoke during pregnancy (16\%) is still at the same level as in the late 1980s. Smoking during pregnancy is more common in younger women and, in 2012, half of the pregnant women aged under 20 years old smoked during pregnancy. The share was $10 \%$ among women aged over 35 . In 2012, 42\% of all parturients reported quitting smoking during the first trimester of pregnancy, while the number was $16 \%$ in 2002 [2].

Smoking during pregnancy has been associated with an increased risk e.g. for miscarriage, ectopic pregnancy, fetal growth restriction, placenta previa, preterm birth, and low birth weight $[1,4]$. In previous research, prematurity and fetal growth restriction are the areas of most concern. Cessation of smoking during pregnancy results in the reduction of low birth weight, fetal growth restriction, and preterm birth, and thus attributes to a decreased risk for perinatal death and improved neonatal outcomes [1].

It is known that maternal age has increased and continues to grow in many Western countries over the last few years. Several studies have indicated a connection between advanced maternal age of over 35 years and adverse perinatal outcomes as well as an increased risk for certain pregnancy complications. In Finland, the proportion of parturients aged over 35 is increasing and was $19.5 \%$ in 2012 [2]. In 2010, the percentages of smoking pregnant women aged over 35 years old were higher for example in Denmark (21\%), Luxembourg (24\%), Ireland (28\%), and Spain (30\%), and lower being 11\% in Bulgaria and $12 \%$ in Poland [5].

Adverse pregnancy outcomes related to older maternal age and smoking have been reported in earlier studies [6-8]. It has been suggested that vulnerability to the negative effects of smoking on birth weight increase with age [8]. Most of the previous studies have concentrated on a few pregnancy outcomes like small for gestational age and low birth weight. In the present study, we compared pregnancy outcomes among smoking and nonsmoking pregnant women aged less than 35 years, and 35 or older.

\section{Methods}

The data for this study consist of the information from Finnish Medical Birth Register (MBR), Hospital Discharge
Register (HDR), and The Register of Congenital Malformations. Researchers can apply for the authorization for the use of same health register data for scientific research from the register keeping organization (THL National Institute for Health and Welfare), which granted the access to the health register data for this study in September 2009.

The Finnish Medical Birth Register is a populationbased registry established in 1987 and is currently compiled by the National Institute for Health and Welfare (THL). The MBR includes information on maternal and neonatal birth characteristics and perinatal outcomes for all women giving birth in Finland and all newborns up to seven days of age. The form is filled by the hospital and sent, mostly electronically, to THL [9].

The Hospital Discharge Register was established in 1969 and it contains information on all aspects of impatient care in public and private hospital visits and outpatient visits to public hospitals (since 1998). Hospitals send data electronically to THL [10].

The Register of Congenital Malformations is run by THL and it contains data on congenital chromosomal and structural anomalies detected in stillborn and live born infants and fetuses in pregnancies terminated due to suspected or confirmed congenital anomaly in Finland nationwide. The Register was established in 1962 and registration of anomaly data began in 1963 [11].

\section{Participants}

The original obtained data contains information on 690 555 women and their newborns between the years 19972008. The study population of the current study was selected from the original data and included women who were smoking during pregnancy $(\mathrm{N}=80260)$. Nonsmoking women aged less than 35 years old were used as a reference group $(\mathrm{N}=460356)$. Cases with congenital anomalies were excluded (Figure 1). We compared women aged 35 years or older to women aged less than 35 years old.

Women's smoking status was classified into four categories: non-smoker, quit smoking after first trimester, smoker, and cases where the smoking status remained unknown. Smoking status was self-reported and only women who were reported to be smokers were included in the smoking category. Women who reported quitting smoking during the first trimester were classified into the non-smoking category.

\section{Statistical analysis}

The statistical analysis was conducted using SPSS for Windows, version 17. The following definitions were used to record pregnancy outcomes: preterm delivery, before 37 weeks of gestation; low Apgar score at $1 \mathrm{~min}$., Apgar score <7; low birth weight (LBW), less than 2500 g; 


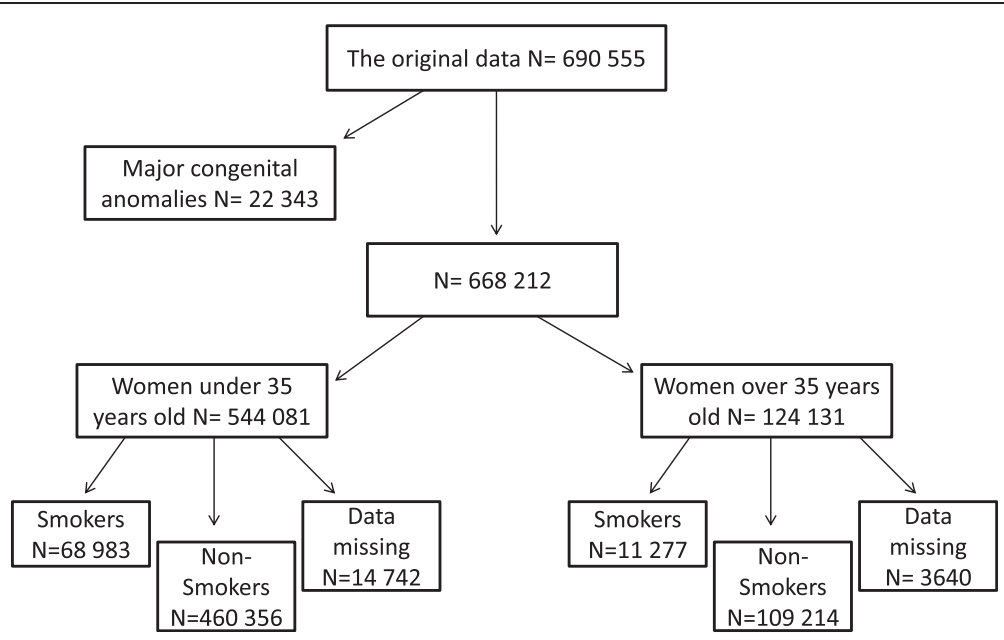

Figure 1 Data flow in the current study.

small for gestational age (SGA), infants were considered small when the sex-and age-adjusted birth weight was below the tenth percentile according to the standard tables for the Finnish population data for all births [12].

Statistical differences were evaluated using chi-square tests for dichotomous variables; continuous variables were analyzed using independent sample t-tests. All variables used in the binary logistic regression analysis were dichotomous and missing data for any variable were categorized as "no" $(=0)$. Cases with anomalies were removed from the data. Binary logistic regression adjusted for potential confounding factors included smoking, preeclampsia, IVF, other fertility treatment than IVF, and pre-gravid $\mathrm{BMI}>25$. Because maternal height and weight have been recorded in the data sources only since 2004, logistic regression is presented primarily without BMI. In order to compare the pregnancy outcomes of smoking and non-smoking women aged less than 35 years and 35 or older, we estimated the odds ratios and $95 \%$ confidence intervals. Non-smoking women aged less than
35 years was first used as the reference group to compare all four groups [13]. Then smoking women aged 35 years or older were compared separately first to smoking women aged less than 35 years as a reference group and then to non-smoking women aged 35 years or older as a reference group.

\section{Results}

In the original data $(\mathrm{N}=690555)$, there were 80260 (12\%) women who were smoking during pregnancy, of whom 11277 (9\%) were aged 35 years or older and 68 $983(13 \%)$ were less than 35 years old (Figure 1).

The mean ages of the group of women aged less than 35 years old who were smoking was 27.9 (SD 4.7) and with non-smokers 25.7 (SD 3.9), while in the women aged 35 years or older the means were the same for smokers and non-smokers: 37.5 (SD 2.3).

The group of women aged less than 35 years with non-smokers and smokers differed in pre-gravid BMI, late pregnancy bleeding, anemia, fertility treatment other

Table 1 Background information of non-smoking and smoking pregnant women aged <35 years and $\geq 35$ years old

\begin{tabular}{|c|c|c|c|c|c|c|}
\hline & $<35 y$ non-smoker & Smoker & $P$ & $\geq 35 y$ non-smoker & Smoker & $P$ \\
\hline Maternal diabetes (N/\%) & $15834(3.4)$ & $2471(3.6)$ & $<.056$ & $6535(6.0)$ & $715(6.3)$ & $<.129$ \\
\hline Pregravid BMl $>25 \mathrm{~kg} / \mathrm{m}^{2}$ (N/\%) & $49107(29.4)$ & $8049(35.0)$ & $<.001$ & $14483(37.1)$ & $1529(45.2)$ & $<.001$ \\
\hline Placenta previa (N/\%) & $935(0.2)$ & $158(0.2)$ & $<.162$ & $457(0.4)$ & $44(0.4)$ & $<.657$ \\
\hline Late pregnancy bleeding (N/\%) & $6578(1.4)$ & $1141(1.7)$ & $<.001$ & $1826(1.7)$ & $250(2.2)$ & $<.001$ \\
\hline Anemia (N/\%) & $3327(0.7)$ & $579(0.8)$ & $<.001$ & $855(0.8)$ & $68(0.6)$ & $<.037$ \\
\hline Unmarried (N/\%) & $156358(34.0)$ & $43740(63.4)$ & $<.001$ & $30367(27.8)$ & $5829(51.7)$ & $<.001$ \\
\hline Fertility treatment other than IVF (N/\%) & $6233(1.4)$ & $348(0.5)$ & $<.001$ & $3264(3.0)$ & $139(1.2)$ & $<.001$ \\
\hline IVF (N/\%) & $5753(1.2)$ & $297(0.4)$ & $<.001$ & $3553(3.3)$ & $141(1.3)$ & $<.001$ \\
\hline Preeclampsia (N/\%) & 21954(4.8) & $2400(3.5)$ & $<.001$ & $6400(5.9)$ & $535(4.7)$ & $<.001$ \\
\hline
\end{tabular}




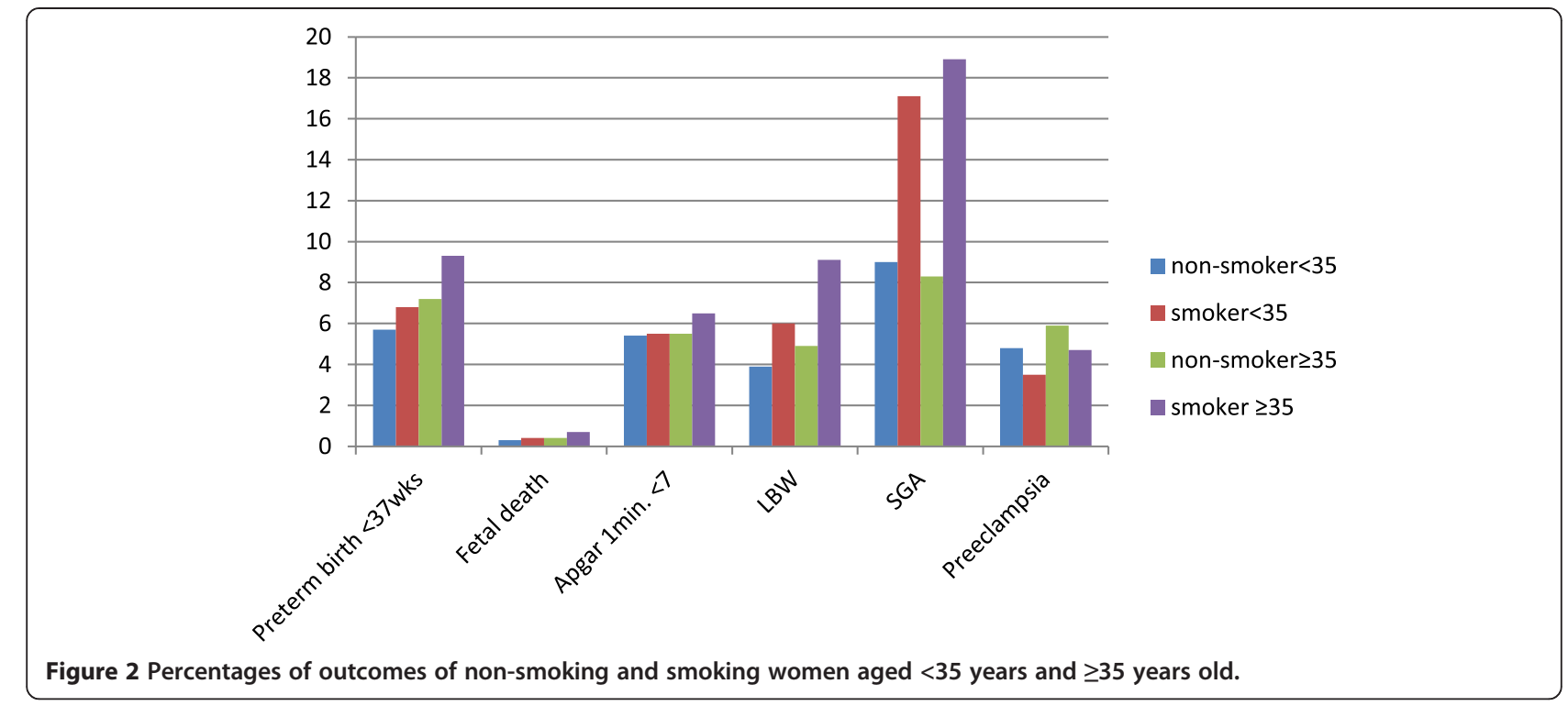

than IVF and IVF, preeclampsia, and being unmarried. The group of women aged 35 years or older with nonsmokers and smokers differed in pre-gravid BMI, late pregnancy bleeding, fertility treatment other than IVF and IVF, preeclampsia, and being unmarried.

Table 1 summarizes the background information of the four groups.

The mean weight before pregnancy in the group of under 35-year-olds was 66.4 kg (SD $15.1 \mathrm{~kg}$ ) in smokers and $65.8 \mathrm{~kg}$ in non-smokers (SD $13.3 \mathrm{~kg}$ ). The mean weight in the group of women aged 35 years or older was $70.0 \mathrm{~kg}$ in smokers (SD $15.1 \mathrm{~kg}$ ) and $68.4 \mathrm{~kg}$ in nonsmokers (SD $13.6 \mathrm{~kg}$ ). The mean birth weight was $3532 \mathrm{~g}$ (SD $568 \mathrm{~g}$ ) in women aged less than 35 who were non-smokers and $3358 \mathrm{~g}$ (SD $573 \mathrm{~g}$ ) in smokers. In the group of smoking women aged 35 years or older, the mean birth weight was $3302 \mathrm{~g}$ (SD $651 \mathrm{~g}$ ) and $3536 \mathrm{~g}$ (SD $618 \mathrm{~g}$ ) in non-smokers.

Percentages of outcomes among non-smoking and smoking women aged less than 35 years and 35 years or older are shown in Figure 2.
The incidence of preterm delivery, SGA and LBW was higher in pregnant women aged less than 35 years old who smoked. Non-smoking women aged 35 years or older had higher rates of preterm delivery, fetal death, preeclampsia and LBW compared to non-smoking women aged less than 35 years (Table 2).

In the group of smoking women aged 35 years or older, SGA, fetal death and LBW were found to occur twice as often compared to non-smoking women aged less than 35 years old. The incidence of preterm delivery was significantly higher as well (Table 2).

Comparison between smoking women aged 35 years or older and smoking women less than 35 years is shown in Table 3, where the impact of maternal age was also found to be significant among smoking women with regard to preterm delivery, SGA and low birth weight. In the same vein of thought, the differences between women aged 35 years or older compared and their non-smoking counterparts preterm delivery, low Apgar scores at $1 \mathrm{~min}$, LBW, SGA and fetal death were all found to be higher in the smoking women (Table 4).

Table 2 Pregnancy outcomes in non-smoking and smoking women aged $<35$ and $\geq 35$ years old

\begin{tabular}{llllll}
\hline Outcome & \multicolumn{4}{l}{ Adjusted OR and 95\% Cl } & \\
\cline { 2 - 6 } & $<$ 35non-smoker & $<35$ smoker & $\mathbf{3}$ 35non-smoker & $\geq 35$ smoker \\
\hline Preterm delivery <28wk & 1 & $1.29,1.27-1.34\left({ }^{*} 1.27,{ }^{*} 1.20-1.35\right)$ & $1.17,1.14-1.21\left({ }^{*} 1.15,{ }^{*} 1.10-1.20\right)$ & $1.73,1.61-1.85\left({ }^{*} 1.60,{ }^{*} 1.40-1.82\right)$ \\
SGA(<90th percentile) & 1 & $2.14,2.09-2.19\left({ }^{*} 2.18,{ }^{*} 2.10-2.26\right)$ & $0.91,0.89-0.93\left({ }^{*} 0.91,{ }^{*} 0.88-0.95\right)$ & $2.38,2.27-2.51\left({ }^{*} 2.55,{ }^{*} 2.34-2.79\right)$ \\
Low birth weight $(<2500 \mathrm{~g})$ & 1 & $1.74,1.68-1.80\left({ }^{*} 1.73,{ }^{*} 1.62-1.84\right)$ & $1.15,1.11-1.19\left({ }^{*} 1.13,{ }^{*} 1.07-1.19\right)$ & $2.60,2.43-2.78\left({ }^{*} 2.50,{ }^{*} 2.20-2.80\right)$ \\
Fetal death & 1 & $1.39,1.22-1.58\left({ }^{*} 1.18,{ }^{*} 0.92-1.15\right)$ & $1.37,1.23-1.53\left({ }^{*} 1.36,{ }^{*} 1.12-1.64\right)$ & $2.57,2.06-3.22\left({ }^{*} 2.70,{ }^{*} 1.80-4.05\right)$ \\
Low Apgar score $(<7)$ at 1 min. & 1 & $1.03,1.00-1.07\left({ }^{*} 1.02,{ }^{*} 0.96-1.01\right)$ & $0.97,0.94-1.00\left({ }^{*} 0.95,{ }^{*} 0.90-0.99\right)$ & $1.21,1.11-1.30\left({ }^{*} 1.12,{ }^{*} 0.97-1.30\right)$ \\
Preeclampsia & 1 & $0.73,0.70-0.76\left({ }^{*} 0.78,{ }^{*} 0.72-0.84\right)$ & $1.20,1.17-1.24\left({ }^{*} 1.14,{ }^{*} 1.09-1.20\right)$ & $1.00,0.91-1.09\left({ }^{*} 0.90,{ }^{*} 0.77-1.06\right)$ \\
\hline
\end{tabular}

(*BMl included). 
Table 3 Outcomes of $<35$ year-old smoking and $\geq 35$ year-old smoking women

\begin{tabular}{llll}
\hline Outcome & $<35$ smokers & $\mathbf{2 3 5}$ smokers & Adjusted OR and 95\% Cl \\
\hline Preterm delivery (before $37 \mathrm{wk})$ & $4425(5.9 \%)$ & $975(1.3 \%)$ & $1.35,1.25-1.45\left({ }^{*} 1.29,{ }^{*} 1.12-1.48\right)$ \\
SGA $\left(<90^{\text {th }}\right.$ percentile) & $11430(14.7 \%)$ & $2043(2.6 \%)$ & $1.12,1.07-1.19\left({ }^{*} 1.18,{ }^{*} 1.07-1.29\right)$ \\
Low birth weight $(<2500 \mathrm{~g})$ & $4120(5.1 \%)$ & $1027(1.3 \%)$ & $1.51,1.41-1.62\left({ }^{*} 1.50,{ }^{*} 1.31-1.71\right)$ \\
Fetal death & $273(0.3 \%)$ & $83(0.1 \%)$ & $1.87,1.46-2.40\left({ }^{*} 2.36,{ }^{*} 1.49-3.73\right)$ \\
Low Apgar score $(<7)$ at $1 \mathrm{~min}$. & $3589(4.7 \%)$ & $692(0.9 \%)$ & $1.17,1.08-1.27\left({ }^{*} 1.09,{ }^{*} 0.94-1.27\right)$ \\
Preeclampsia & $2400(3.0 \%)$ & $535(0.7 \%)$ & $1.37,1.24-1.50\left({ }^{*} 1.17,{ }^{*} 0.98-1.39\right)$ \\
\hline
\end{tabular}

(* BMl included).

\section{Discussion}

The aim of this study was to examine pregnancy outcomes among smoking and non-smoking pregnant women aged less than 35 years and 35 years or older.

There were fewer women who were smoking during pregnancy among women aged 35 years or older that in the group of women under 35, but the former groups' behavioural risk profile and outcome results clearly demonstrated that older smoking women are a distinct high risk group.

Smoking increased the risks of preterm birth, SGA, $\mathrm{LBW}$, and fetal death in all pregnant women, but even more so in older women.

Maternal age of 35 years or more independently of smoking appeared to increase the risks of preterm delivery, fetal death, preeclampsia and LBW. However, the combination of maternal age of 35 years or more and smoking was significantly increasing the risks of these outcomes in the subgroup analyses performed, showing that the two independent risks, smoking and advanced maternal age, are additive. This reflected two important health issues. First, advanced maternal age alone increased the risk of adverse pregnancy outcome. Second, the high risk group identified by maternal smoking was smaller but even less health conscious in the case of older than younger women. In other words, smoking is a more powerful marker of risky health behaviour among older than younger women.

The incremental risk caused by smoking was clearly higher in older than in younger women in all studied outcomes, even though the effect on fetal growth was clinically the most important.

Our findings are in line with previous studies reporting adverse pregnancy outcomes in smoking women $[4,6-8,14]$ and especially with the one reporting that the smoking-related risk of SGA increases with maternal age $[7,14]$. Smoking during pregnancy is an important health problem associated with adverse outcomes, particularly fetal growth restriction and preterm birth, which can both have far-reaching health consequences into adult life [15].

The toxic effects of smoking may influence fetal growth more among older smoking women and the longer exposure in the mother to the harmful effects of smoking may also be more damaging to the fetus $[7,14]$.

In the present study, older women who were smoking were more often overweight than their non-smoking counterparts, but they had had less infertility treatments than non-smokers. On the other hand, smoking and obesity are known to impair fertility. The discrepancy between the known increasing rate of fertility problems and the observed underuse of fertility treatments probably reflected the fact that smokers were less health conscious and sought health care less often than their non-smoking counterparts. In the present study, the study population of the older smoking pregnant women seems to have been positively selected due to their successful pregnancy in spite of the smoking-related risks affecting fertility altogether.

In the present study, smokers were more often unmarried. Married adults are considered to be in better health than unmarried ones and the economic situation of

Table 4 Outcomes of non-smoking and smoking women aged $\geq 35$ years old

\begin{tabular}{llll}
\hline Outcome & $\geq 35$ non-smokers & $\mathbf{2 3 5}$ smokers & Adjusted OR and 95\% Cl \\
\hline Preterm delivery (before $37 \mathrm{wk})$ & $7399(7.2 \%)$ & $975(9.3 \%)$ & $1.44,1.34-1.55\left({ }^{*} 1.34,{ }^{*} 1.17-1.53\right)$ \\
SGA $\left(<90^{\text {th }}\right.$ percentile) & $8693(8.3 \%)$ & $2043(18.9 \%)$ & $2.65,2.51-2.80\left(^{*} 2.83,{ }^{*} 2.58-3.12\right)$ \\
Low birth weight $(<2500 \mathrm{~g})$ & $5337(4.9 \%)$ & $1027(9.1 \%)$ & $2.20,2.06-2.37\left(^{*} 2.15,{ }^{*} 1.88-2.46\right)$ \\
Fetal death & $438(0.4 \%)$ & $83(0.7 \%)$ & $1.85,1.46-2.34\left({ }^{*} 1.93,{ }^{*} 1.26-2.96\right)$ \\
Low Apgar score $(<7)$ at 1 min. & $5667(5.5 \%)$ & $692(6.5 \%)$ & $1.24,1.14-1.34\left(^{*} 1.18,{ }^{*} 1.02-1.36\right)$ \\
Preeclampsia & $6400(5.9 \%)$ & $535(4.7 \%)$ & $0.83,0.66-0.93\left({ }^{*} 0.78,{ }^{*} 0.76-0.91\right)$ \\
\hline
\end{tabular}

(* BMI included). 
unmarried women is also likely to be worse than of those who are married. Poor health consciousness and smoking are related to being less well-educated and more often unemployed with more alcohol consumption, pregnancy terminations, and untreated infections $[16,17]$.

It has been reported that women who smoke during pregnancy tend to under-report their smoking [18]. Maternal under-reporting has significant implications on the validity of research in this area, producing underestimates of smoking prevalence and overestimates of the non-smoking/quit smoking status [19]. It is also possible that older pregnant women report smoking more accurately than younger ones [8]. However, the strength of this study is a large population-based register data comprising almost 700000 births. It has been shown in several studies comparing the internal validity that, in Finnish health registries, the validity and coverage are good as all events are included in the data and the registries comply with reality [20]. The information of health registries provide a highly complete and high-quality source of information that can be utilized, for example, in scientific research [21].

It has been suggested that smoking acts as a marker for other unhealthy habits, exposures, or differences in behaviour or socioeconomic status, but they cannot be measured using birth certificates or registries [8]. However, in Finland, pregnant women are relatively homogenous and they receive similar antenatal and obstetric care, in which case the influence of socioeconomic factors on pregnancy outcome is limited.

The results of the current study suggest and confirm earlier implications that, especially from a public health viewpoint, more attention should be paid to older smoking women during their pregnancy due to an increased risk for impaired fetal growth and preterm delivery as well as other adverse pregnancy outcomes that are harmful to the newborn. In one study, 70\% of those who smoked during their first pregnancy continued smoking in a sequential pregnancy, which highlights the importance of smoking cessation during the first pregnancy [22].

\section{Conclusions}

Cessation of smoking should be monitored and support should be given during the first trimester of pregnancy especially to the older smokers. It can be presumed that older smoking pregnant women smoke while consciously ignoring the pregnancy-related risks. Therefore, the cessation of smoking post pregnancy is unlikely. Maternity care should identify and concentrate on these groups of women who clearly have health behavioural issues that can harm pregnancy.

\section{Competing interests}

The authors declare that they have no competing interest.

\section{Authors' contributions}

$\mathrm{RL}$ conceived the study with contributions from SH and KVJ. RL prepared the data and performed the statistical analysis. $\mathrm{RL}$ and $\mathrm{SH}$ interpreted the results with contributions from KVJ and MG. RL reviewed the literature and wrote the manuscript. SH, KVJ and MG critically revised the manuscript for scientific quality and content. All authors approved the final version for publication.

\section{Acknowledgements}

This study was supported by the University of Eastern Finland, Department of Nursing Science, The Finnish Doctoral Programme in Nursing Science and Emil Aaltonen foundation. The funding sources were not involved in the study design, interpretation of results, manuscript preparation, or the decision to submit the article for publication.

\section{Author details}

${ }^{1}$ Department of Nursing Science, University of Eastern Finland, P.O.Box. 1627, 70211 Kuopio, Finland. ${ }^{2}$ Department of Nursing Science, University of Eastern Finland and Kuopio University Hospital, Kuopio, Finland. ${ }^{3}$ National Institute for Health and Welfare (THL), Helsinki, Finland. ${ }^{4}$ Department of Obstetrics and Gynaecology, Kuopio University Hospital and University of Eastern Finland, Kuopio, Finland.

Received: 23 April 2013 Accepted: 27 November 2013

Published: 13 December 2013

\section{References}

1. Tolosa JE, Saade G: Tobacco, alcohol and environment. In Protocols for high-risk pregnancies. 5th edition. Edited by Queenan JT, Hobbins JC, Spong CY. West Sussex, UK: Wiley-Blackwell; 2010:26-36.

2. THL. 2013. http://www.thl.fi/fi_Fl/web/fi/tilastot/aiheittain/seliterveys/ synnytykset/perinataalitilasto.

3. Tikkanen M: Tupakointi ja raskaus. Duodecim 2008, 124:1224-1229.

4. Wen S, Goldenberg R, Cutter G, Hoffman H, Cliver S, Davis R, DuBard M: Smoking, maternal age, fetal growth and gestational age at delivery. Am J Obstet Gynecol 1990, 162(1):53-58.

5. WHO: Health for all -database. Copenhagen, Denmark: WHO Regional Office for Europe; 2012. July 2013 http://www.euro.who.int/en/data-and-evidence/ databases/european-health-for-all-database-hfa-db.

6. Cnattingius S, Forman M, Berendes H, Graudbard B, Isotalo L: Effect of age, parity and smoking on pregnancy outcome: a population-based study. Am J Obstet Gynecol 1993, 168(1):16-21.

7. Cnattingius S, Axelssons O, Eklund G, Lindmark G: Smoking, maternal age and fetal growth. Obstet Gynecol 1985, 66(4):449-452.

8. Fox S, Koepsell T, Daling J: Birth weight and smoking during pregnancy effect modification by maternal age. Am J Epidemiol 1994, 139(10):1008-1015.

9. The National Institute for Health and Welfare. 2010. Available at: http:// www.thl.fi/fi_Fl/web/fi/tilastot/aiheittain/rekisteriselosteet/syntyneet_lapset (retrieved April 14, 2011).

10. The National Institute for Health and Welfare. 2011. Available at: http://www. thl.fi/fi_Fl/web/fi/tilastot/tiedonkeruut/hilmo (retrieved April 14, 2011).

11. The National Institute for Health and Welfare. 2011. Available at: http://www. thl.fi/fi_Fl/web/fi/tilastot/tietoa/rekisteriselosteet/epamuodostumat (retrieved April 14, 2011).

12. Heinonen S, Taipale P, Saarikoski S: Weights for Placentae from small-forgestational age infants revisited. Placenta 2001, 22:399-404.

13. Miller E, Huiling S, Wu Wen S, Yang Q, Lafleche J, Walker M: The risk of adverse pregnancy outcomes is increased in preeclamptic women who smoke compared with nonpreeclamptic women who do not smoke. AJR Am J Obstet Gynecol 2010, 203(4):334. el-334.e8.

14. Cnattingius S: Maternal age modifies the effect of maternal smoking on intrauterine qrowth retardation but not on late fetal death and placental abruption. Am J Epidemiol 1997, 145(4):319-323.

15. Bickerstaff $M$, Beckmann M, Gibbons K, Flenady V: Recent cessation of smoking and its effect on pregnancy outcomes. Aust N Z J Obstet Gynaecol 2012, 52(1):54-58.

16. Raatikainen $\mathrm{K}$, Heiskanen N, Heinonen S: Marriage still protects pregnancy. BJOG 2005, 112(10):1411-1416.

17. Raatikainen $K$, Huurinainen P, Heinonen S: Smoking in early gestation or through pregnancy: a decision crucial to pregnancy outcomes. Prev Med 2007, 44(1):59-63. 
18. Goldenberg R, Klerman L, Windsor R, Whiteside H: Smoking in pregnancy: final thoughts. Tob Control 2000, 9(3):iii85-iii86.

19. Salihu H, Aliyu M, Pierre-Louise B, Alexander G: Levels of excess infant deaths attributable to maternal smoking during pregnancy in the United States. Matern Child Health J 2003, 7(4):219-227.

20. Gissler M, Haukka J: Finnish health and social welfare registers in epidemiological research. Norsk Epidemiologi 2004, 14(1):113-120.

21. Gissler M, Surcel H-M: Combining health register data and biobank data. Stat J IAOS 2012, 28:53-58.

22. Cnattingius $\mathrm{S}$, Akre O, Lambe M, Ockene J, Granath F: Will an adverse pregnancy outcome influence the risk of continued smoking in the next pregnancy. Am J Obstet Gynaecol 2006, 195(6):1680-1686.

doi:10.1186/1471-2458-13-1179

Cite this article as: Lamminpää et al: Smoking among older childbearing women - a marker of risky health behaviour a registry-based study in Finland. BMC Public Health 2013 13:1179.

\section{Submit your next manuscript to BioMed Central and take full advantage of:}

- Convenient online submission

- Thorough peer review

- No space constraints or color figure charges

- Immediate publication on acceptance

- Inclusion in PubMed, CAS, Scopus and Google Scholar

- Research which is freely available for redistribution 